\title{
EL PRONUNCIAMIENTO DEL TRIBUNAL CONSTITUCIONAL SOBRE EL PREÁMBULO DEL ESTATUTO DE AUTONOMÍA DE CATALUÑA: NACIÓN, REALIDAD NACIONAL Y DERECHOS HISTÓRICOS
}

\author{
JAVIER TAJADURA TEJADA \\ Profesor Titular de Derecho Constitucional \\ Universidad del País Vasco
}

\author{
SUMARIO \\ I. Introducción. \\ II. La idoneidad del Preámbulo para ser objeto de \\ un pronunciamiento del Tribunal Constitu- \\ cional. \\ III. La privación de eficacia jurídica interpretativa \\ a las referencias a la Nación y a la realidad \\ nacional de Cataluña. \\ IV. El pronunciamiento del Tribunal sobre los \\ «derechos históricos». \\ V. Conclusiones.
}

\section{INTRODUCCIÓN}

En uno de los primeros comentarios sobre la STC 31/2010, Muñoz Machado acertadamente advertía que «el Tribunal, aun sin actuar como legislador negativo — que le hubiera obligado a formular la declaración directa de nulidad de las regulaciones estatutarias incompatibles con la Constitución — ha acabado con cualquier pretensión de que las expresiones nación (en el Preámbulo), derechos históricos y pueblo catalán (en el texto), puedan entenderse como significantes de que el Estatuto de Cataluña procede de una fuente de legitimidad propia e histórica, precedente y distinta a la Constitución de 1978» ${ }^{\circledR}$.

1 MuÑoz Machado, S.: La verdad sobre el caso del Estatut II, en El Imparcial, 6 de julio de 2010. 
Sirva esta advertencia para poner de manifiesto que, en contra de lo que algunos sostienen, el pronunciamiento del Tribunal Constitucional sobre los categorías de «realidad nacional» y de «derechos históricos» de Cataluña dista mucho de ser irrelevante. Antes al contrario, el examen del mismo va a poner de manifiesto que no nos encontramos ante un debate esteril por nominal, sino ante la controversia fundamental en torno al nuevo Estatuto, esto es, la relativa a su legitimidad.

Concretamente, en el recurso de inconstitucionalidad interpuesto contra el Estatuto de Autonomía de Cataluña se impugnaban los siguientes párrafos del Preámbulo del Estatuto:

«El autogobierno de Cataluña se fundamenta en la Constitución así como en los derechos históricos del pueblo catalán que, en el marco de aquélla, dan origen en este Estatuto al reconocimiento de una posición singular de la Generalitat».

«El Parlamento de Cataluña, recogiendo el sentimiento y la voluntad de la ciudadanía de Cataluña, ha definido de forma ampliamente mayoritaria a Cataluña como nación. $L a$ Constitución española, en su artículo segundo, reconoce la realidad nacional de Cataluña como nacionalidad».

La referencia última al «ejercicio del derecho inalienable de Cataluña al autogobierno».

En relación con estas impugnaciones, el fallo de la sentencia se inicia con un primer apartado en el que el Tribunal declara que «carecen de eficacia jurídica interpretativa las referencias del Preámbulo del Estatuto de Cataluña a «Cataluña como nación» y a «la realidad nacional de Cataluña'». Y ello porque como se sostiene en el Fundamento Jurídico 12 que analizaremos después la Constitución —en sentido jurídico-constitucional— no reconoce más nación que la española.

Con este expreso pronunciamiento llevado al encabezamiento del fallo el Tribunal deja claro que el Preámbulo de una Ley también puede ser objeto de control de constitucionalidad y rechaza la tesis de aquellos que, en sede política y académica, sostenían que por carecer de valor jurídico no podía ser objeto de impugnación.

El Tribunal analiza en su sentencia el contenido de las disposiciones preambulares impugnadas y coteja su significado y alcances jurídicos con el contenido del artículo dos de la Constitución. Su conclusión es que las referencias a Cataluña como nación y a la realidad nacional de Cataluña resultan incompatibles con el citado artículo constitucional. Ahora bien, siguiendo la que va a ser la técnica habitual que marcará la sentencia, el Tribunal no deduce de esa incompatibilidad, la declaración de inconstitucionalidad y consiguiente nulidad de las disposiciones impugnadas, sino tan sólo su falta de eficacia. Y es que, si algo caracteriza a esta sentencia, es el hecho de llevar a sus últimas consecuencias la tan novedosa como asombrosa doctrina alumbrada en la sentencia que resolvió las impugnaciones del Estatuto de Valencia consistente en distinguir validez y eficacia. En virtud de esa distinción, comprobado que un determinado precepto legal es contrario a la Constitución, el Tribunal puede «administrar» las consecuencias de ese juicio y no está obligado a declarar su nulidad, pudiendo en cambio limitarse a declarar su ineficacia. Comentando aquella sentencia ya señalé que no existe base jurídica alguna para formular tal distinción en un juicio de constitucionalidad y que si el Tribunal llega a la conclusión de que un precepto legal es contrario a la Constitución — dejando a un lado los supuestos de inconstitucionalidad por omisión parcial- está obligado a declarar su nulidad y expulsarlo del ordenamiento jurídico ${ }^{2}$.

2 TAjadura, J.: «El Tribunal Constitucional y las reformas estatutarias: a propósito de la STC 247/2007 
El Tribunal — por las razones que analizaremos a continuación — va a concluir con meridiana claridad y evidente acierto que las disposiciones preambulares son contrarias a la Constitución. Y por ello les va a privar de «eficacia jurídica interpretativa». Ahora bien, dado el valor normativo de un Preámbulo que no es un valor normativo directo sino indirecto, esto es hermeneútico, privarle de este efecto es tanto como anularlo. Dicho con otras palabras, proclamar que una disposición preambular carece de eficacia jurídica interpretativa conduce al mismo resultado que la anulación de dicha disposición.

Y si esto es así, no se acierta a comprender las razones por las que el Tribunal no declaró expresamente esa nulidad. El único argumento que, por lo dicho antes no me parece sólido, consiste en afirmar que una disposición contraria a la Constitución puede ser ineficaz pero no inválida. Argumento que rechazan cuatro magistrados en sus votos particulares.

Los votos particulares formulados por cuatro magistrados discrepantes coinciden con la mayoría en afirmar que las disposiciones preambulares impugnadas son inconstitucionales. Y esto es algo que es preciso subrayar: existe unanimidad en el Tribunal sobre este particular. La discrepancia reside en el hecho de que los cuatro magistrados discrepantes — de la misma forma que el autor de este comentario- no entienden como advertida la inconstitucionalidad puede eludirse la declaración de nulidad.

Sea de ello lo que fuere, lo cierto es que con esta declaración, se desactiva en buena manera, la que podríamos considerar inconstitucionalidad global del texto estatutario en la medida en que pudiera exigir ser interpretado como una norma fundamental emanada de un poder originario: una nación dotada de unos derechos históricos y de un derecho inalienable al autogobierno, y no como una norma derivada de la Constitución y que sólo en ella y en el poder constituyente del pueblo español encuentra su único y exclusivo fundamento.

Con estas premisas, en este comentario vamos a analizar las siguientes cuestiones: a) en primer lugar, la idoneidad del Preámbulo para ser objeto de un pronunciamiento del Tribunal Constitucional; b) en segundo lugar, el significado y alcance de la declaración contenida en el apartado primero del fallo sobre la privación de eficacia jurídica interpretativa a las referencias a la nación y a la realidad nacional de Cataluña; c) en tercer lugar, el pronunciamiento del Tribunal sobre los «derechos históricos».

\section{LA IDONEIDAD DEL PREÁMBULO PARA SER OBJETO DE UN PRONUNCIAMIENTO DEL TRIBUNAL CONSTITUCIONAL (FJ 7).}

Como anticipamos en la introducción las consecuencias de privar de eficacia jurídica interpretativa a una disposición preambular son las mismas que se derivan de su pura y simple anulación. Creo por ello oportuno detenerme a desarrollar este argumento puesto que es el que va a justificar mi crítica a la decisión del Tribunal de no proceder a la anulación de las citadas disposiciones.

sobre el Estatuto de Autonomía de la Comunidad Valenciana» en Treinta años de Constitución, GarCia RocA, J., y Alberti, E. (Coords.), Tirant Lo Blanch, Valencia, 2010, págs. 225-255. 


\section{II.1. VAlor JuRídico de los PreÁmbulos}

En nuestro Derecho parlamentario, una vez superada la fase de iniciativa legislativa, las exposiciones de motivos pierden su carácter obligatorio (art. $88 \mathrm{CE}$ ) y pasan a ser consideradas, a los efectos de su tramitación parlamentaria, y para su eventual incorporación a la ley como Preámbulo de la misma, como un artículo más de la ley, susceptible de todo tipo de enmiendas (Artículo 110. 5 del Reglamento del Congreso). Por ello hay que afirmar que el eventual preámbulo no tiene porque coincidir en su contenido con la exposición de motivos inicial. Es más, si el sentido de la ley ha sido alterado por modificaciones sustanciales del articulado de la norma, lo lógico y consecuente es que el preámbulo haya sido corregido en la misma dirección. Por esta razón teleológica es necesario que el debate y votación del preámbulo se produzcan una vez fijado ya el articulado de la ley. Podemos así definir un preámbulo como el texto introductorio que precede al articulado de un documento normativo y que presentándolo expone las razones por las cuales el autor de la norma interviene como tal así como los objetivos que con su actuación persigue. El preámbulo se configura así como un elemento que pone de manifiesto la continuidad de todo orden jurídico al conectar el pasado - la situación de partida que motiva la puesta en marcha del procedimiento legislativo - con el futuro, - la exposición de los fines a alcanzar- descripción de la situación a la que se aspira llegar-. En este contexto la cuestión fundamental es determinar qué valor jurídico tienen los Preámbulos de las leyes.

El estudio de este problema exige distinguir previamente dos cuestiones: primero, si el preámbulo forma o no parte del texto normativo al que precede; y, segundo, su carácter normativo.

En cuanto a la primera cuestión, no cabe duda de que el preámbulo es parte del texto jurídico en el que se encuentra situado. A favor de esta tesis juegan los siguientes argumentos: a) Los artículos 110.5 y 114.2 del Reglamento del Congreso de los Diputados, al regular el procedimiento legislativo ordinario, consideran las Exposiciones de Motivos de los proyectos de ley como un artículo más a los efectos de su tramitación parlamentaria: pueden ser enmendadas, son discutidas al final del articulado, y pueden incorporarse como preámbulos de las leyes finalmente aprobadas. b) El texto introductorio que precede al articulado figura siempre tras la fórmula de promulgación.

La determinación, por tanto, del valor jurídico del preámbulo, ha de partir del hecho de que éste es parte integrante del texto a cuyo articulado antecede. Esto, no hace falta insistir en ello, no prejuzga la cuestión de si tiene algún género de valor sustantivo y, en particular, si goza o no de valor normativo.

Aunque la doctrina parece decantarse mayoritariamente por negar valor normativo a los preámbulos, es en esta cuestión donde la confusión es mayor. Esa relativa unanimidad en la negativa se expresa de muy distintas formas. Autores hay que lo niegan basándose en el hecho de que los preámbulos no contienen mandatos. Otros no solo niegan el valor normativo sino que incluso llegan a afirmar que los preámbulos no tienen valor jurídico. También hay quien negando su valor normativo mantiene, no obstante, su valor jurídico.

Ahora bien, desde todas las posturas mencionadas se insiste en destacar el valor interpretativo de los preámbulos. Ello hace que el problema se complique puesto que ese valor interpretativo es precisamente lo que justifica para algunos no considerar el preám- 
bulo como una norma o entenderlo desprovisto de valor normativo y para otros es la razón para afirmar su valor jurídico, aunque no normativo.

Nuestra opinión sobre este punto se basa en la distinción conceptual entre disposiciones y normas (CRISAFULLI). Con base en ella puede construirse un concepto de «normatividad» (WROBLESKI) y comprobarse si el mismo es o no predicable de los preámbulos ${ }^{3}$.

Los actos normativos — entendiendo por tales, aquellos actos lingüísticos realizados por órganos competentes que pronuncian enunciados con una finalidad prescriptivadan lugar a documentos normativos - textos que contienen reglas de conducta jurídicamente obligatorias-. Un documento normativo es, por tanto, un conjunto de enunciados con finalidad prescriptiva resultantes de un acto normativo. Cada uno de esos enunciados es una disposición. Toda disposición se entiende así como la fórmula institucionalmente destinada a establecer y manifestar, por medio de su interpretación, la norma. Por tanto, disposición y norma son cosas distintas. La primera es la formulación lingüística de la segunda. La norma se obtiene mediante la interpretación de las disposiciones. Una disposición, por tanto, puede contener varias normas, y a la inversa, una norma puede ser expresada mediante varias disposiciones.

La negación del carácter de disposiciones a los enunciados preambulares, nos exigiría admitir la imposibilidad de que éstos dieran a lugar a normas. Pero ello no es posible. Los enunciados de los preámbulos son disposiciones. Ello es claro dado que son enunciados lingüísticos con significado. Y son disposiciones que, aun formuladas en lenguaje descriptivo, forman parte del texto normativo, y como tal tienen una finalidad prescriptiva. Dos argumentos corroboran esta afirmación: a) En primer lugar, como ya hemos visto, son parte del documento normativo porque los preámbulos se encuentran sistemáticamente ubicados tras la fórmula promulgatoria y son discutidos, enmendados y aprobados como un artículo más. b) En segundo lugar su finalidad prescriptiva se desprende del hecho de que el legislador, cuando actúa como tal, ni informa ni describe, sino que prescribe y todo lo que él emana tiene ab origine ese carácter.

Pero del hecho de que los enunciados preambulares sean disposiciones no se desprende sin más que sean idóneos para extraer de ellos normas jurídicas y por tanto para calificarlos de disposiciones normativas. Como afirma Wroblewski, la discusión relativa a la normatividad de cualquier parte de un texto legal o constitucional solo es significativa después de definir el término «normatividad». Y si por normatividad se entiende, siguiendo al autor citado, que las disposiciones de un texto legal son o bien directamente aplicables (valor normativo directo), o aplicables tras construir algunas normas a partir de estas disposiciones (valor normativo indirecto), debemos analizar si de las disposiciones de los preámbulos cabe predicar tal cosa.

El interrogante acerca del valor normativo de los preámbulos de las leyes queda así planteado en los siguientes términos: ¿Es posible extraer normas jurídicas de las disposiciones preambulares?

En primer lugar la doctrina es prácticamente unánime, y coincidimos con ella, en afirmar que las disposiciones preambulares por sí solas no son fuente de derecho objeti-

3 Crisafulli, V.: «Disposizione (e norma)» en Enciclopedia del diritto, Vol. XIII, Milan, 1964. WroBLESKI, J.: Constitución y teoría general de la interpretación jurídica, Civitas, Madrid, 1985. 
vo, es decir no pueden construirse normas a partir sólo de ellas. De las mismas no cabe extraer derechos ni deberes para los ciudadanos o los poderes públicos, ni pueden ser consideradas como fuente de competencias para ningún órgano del Estado. Los preámbulos no son aptos para regular por sí mismos situaciones y relaciones jurídicas. Esto quiere decir que los preámbulos, como principio general, carecen de valor normativo directo. Ahora bien, las disposiciones preambulares son normativas en la medida en que pueden intervenir en la determinación del significado de las disposiciones del articulado. Los preámbulos tienen así un valor normativo indirecto, en cuanto el intérprete puede obtener la norma valiéndose —o combinando - tanto de las disposiciones del articulado como de las del preámbulo. Por supuesto que nos encontramos con unas disposiciones cuya intensidad normativa es menor que las del articulado, pero se trata de una diferencia de grado y de forma. La diferencia entre las disposiciones del articulado y las del preámbulo reside, por tanto, en que de las primeras cabe extraer normas sólo de ellas, mientras que las segundas necesitan siempre ser combinadas con aquellas para permitir al intérprete extraer una norma.

Las consecuencias que se derivan de esta menor intensidad normativa de las disposiciones preambulares son las siguientes: a) En caso de discrepancia entre disposiciones preambulares y disposiciones articuladas, prevalecen éstas últimas. b) No es posible fundamentar resultados normativos con base exclusivamente en disposiciones preambulares.

En todo caso, por su propia naturaleza, los Preámbulos son un instrumento fundamental para la interpretación teleológica de la ley.

De todo lo expuesto se deduce que la negación de todo valor jurídico a los preámbulos de las leyes es tan incorrecta como la atribución a aquellos de un valor normativo idéntico al del articulado. Las disposiciones preambulares por sí solas no son fuente de derecho objetivo, es decir, no se pueden construir normas a partir sólo de ellas. Ahora bien, las disposiciones preambulares tienen valor normativo en la medida en que pueden intervenir en la determinación del significado de las disposiciones del articulado. Los preámbulos tienen así un valor normativo indirecto, en cuanto el intérprete puede obtener la norma valiéndose —o combinando - tanto de las disposiciones del articulado como de las del preámbulo.

En consecuencia, el debate acerca de la constitucionalidad de un Preámbulo no es un debate irrelevante, como algunos pretendían hacernos creer. Resulta absurdo sostener que una determinada disposición jurídica, por el sólo hecho de estar ubicada en el Preámbulo de una Ley, no pueda ser declarada inconstitucional por el Tribunal Constitucional. Cualquier disposición de una ley — con independencia de que figure en el preámbulo o en el articulado de la misma - puede incurrir en vicios de inconstitucionalidad material. Ello ocurrirá siempre que la interpretación de la disposición conduzca a una norma materialmente inconstitucional. En definitiva, si determinadas disposiciones del Preámbulo del Estatuto catalán, interpretadas conjuntamente con otras del texto articulado, dieran lugar a normas inconstitucionales, el Tribunal Constitucional tendría que anular esas normas, lo que exigiría también invalidar las disposiciones del Preámbulo.

Con otra terminología, esta era también la posición del Tribunal: «el preámbulo no tiene valor normativo» aunque es «un elemento a tener en cuenta en la interpretación de las leyes» (STC 36/1981, de 12 de noviembre. FJ. 7). Ahora bien, a pesar de reconocer- 
le esa eficacia, el Tribunal nunca había realizado y llevado al fallo un juicio de constitucionalidad sobre un texto preambular concreto ${ }^{4}$.

\section{II.2. LA DOCTRINA DEL TRIBUNAL CONSTITUCIONAL SOBRE LA CUESTIÓN}

En la sentencia que ahora nos ocupa el Tribunal toma como punto de partida las premisas antes expuestas. Utilizando otra terminología llega a conclusiones idénticas 5 . Así, en el Fundamento Jurídico 7 insiste en la necesidad ineludible de analizar la constitucionalidad del Preámbulo:

«Los Diputados recurrentes basan su impugnación en una premisa abiertamente discutida por las otras partes procesales, cual es la de la idoneidad misma del Preámbulo para constituirse en objeto de un recurso de inconstitucionalidad. Ciertamente hemos repetido desde la STC 36/1981, de 12 de noviembre, FJ 2, que un «preámbulo no tiene valor normativo» (...) ahora bien, carencia de valor normativo no equivale a carencia de valor jurídico, del mismo modo que la imposibilidad de erigirse en objeto directo de un recurso de inconstitucionalidad no supone que los preámbulos sean inaccesibles a un pronunciamiento de nuestra jurisdicción en tanto que posible objeto accesorio de un proceso referido principalmente a una disposición normativa. De hecho, en la propia STC 36/1981 hicimos una declaración expresa sobre el valor interpretativo del preámbulo entonces examinado, bien que proclamándola en la fundamentación jurídica y sin llevarla formalmente al fallo»

La controversia sobre la idoneidad del Preámbulo para ser objeto de un pronunciamiento del Alto Tribunal queda resuelta. El Tribunal justifica esa idoneidad por la relevancia jurídica que tiene el Preámbulo para la interpretación del Estatuto:

«Nuestro proceder en la citada STC 36/1981 es consecuencia de la naturaleza jurídica de los preámbulos y exposiciones de las leyes, que, sin prescribir efectos jurídicamente obligados y carecer, por ello, del valor preceptivo propio de las normas de Derecho, tienen un valor jurídicamente cualificado como pauta de interpretación de tales normas. Su destinatario es, pues, el intérprete del Derecho antes que el obligado a una conducta que, por definición, el preámbulo no puede imponer. El valor jurídico de los preámbulos de las leyes se agota, por tanto, en su cualificada condición como criterio hermenéutico. Toda vez que, por tratarse de la expresión de las razones en las que el propio legislador fundamenta el sentido de su acción legislativa y expone los objetivos a los que pretende que dicha acción se ordene, constituye un elemento singularmente relevante para la determinación del sentido de la voluntad legislativa, y, por ello, para la adecuada interpretación de la norma legislada».

Establecida esta doctrina que nos parece coherente y acertada, el Tribunal opta por no enjuiciar el Preámbulo en abstracto, y remitir dicho juicio al momento en que vaya a

4 Esta novedad la subraya también Castellà en un sugerente comentario a la sentencia: CASTELLA, J. M.: "La STC 31/2010, sobre el Estatuto de Autonomía de Cataluña y su significado para el futuro del Estado Autonómico», en Documentos de la Fundación Ciudadanía y Valores, septiembre, 2010, pág. 18. www.funciva.org.

5 El Tribunal reitera que el Preámbulo no tiene valor normativo, pero sí valor jurídico. Con ello está queriendo decir que no tiene valor normativo directo, pero sí indirecto. 
analizar determinadas disposiciones del articulado cuya inconstitucionalidad pueda inferirse de su interpretación conjunta y conforme con las disposiciones preambulares:

«En lo que aquí importa, los párrafos del preámbulo del Estatuto de Cataluña cuestionados por los recurrentes lo son por referirse a conceptos y categorías que, proyectadas después a lo largo del articulado, pretenden para el Estatuto, a su juicio, un fundamento y un alcance incompatibles con su condición de norma subordinada a la Constitución. Tales conceptos y categorías son los «derechos históricos», la «nación» y la «ciudadanía», todos ellos formalizados, efectivamente, en diversos preceptos del Estatuto que en conexión con aquéllos también han sido objeto de una impugnación expresa. Ha de ser, por tanto, al hilo del enjuiciamiento de tales preceptos cuando nos pronunciemos también sobre la interpretación de los mismos que eventualmente cupiera deducir de los referidos párrafos del preámbulo y cuando, en consecuencia, de concluir que dicha interpretación es constitucionalmente inadmisible, privemos al preámbulo, en ese punto, del valor jurídico que le es característico, esto es, de su condición de interpretación cualificada».

Esta metodología consistente en remitir el enjuiciamiento del Preámbulo al momento del control de aquellos artículos que son fiel reflejo de sus enunciados es duramente criticada en los votos particulares. Efectivamente, hubiera sido más correcto analizar primero las disposiciones preambulares aunque ello hubiera exigido anticipar el juicio de determinados artículos. Al fin y al cabo, si el Preámbulo es cánon de interpretación de la norma, parece lógico comenzar con su estudio la necesaria tarea de interpretación del Estatuto. En todo caso, el resultado no tendría porque haber sido distinto en uno u otro caso. El método seguido por el Tribunal habría resultado correcto, si se hubiera empleado con la debida coherencia. Efectivamente, el Tribunal sólo puede enjuiciar la constitucionalidad de normas completas, y las disposiciones preambulares per se no conforman normas autónomas. Ahora bien, lo que ocurre es que el Tribunal traiciona su propia metodología, y en esto es en lo que los magistrados discrepantes llevan razón. Precisamente porque la norma enjuiciada resulta de la interpretación conjunta de una disposición preambular y una del texto articulado, el pronunciamiento del Tribunal —sea declarando la constitucionalidad o la inconstitucionalidad - no puede basarse luego en el artificio de la fragmentación de la norma que es lo que ocurre. Artificio mediante el que, asombrosamente, se logra evitar la nulidad de dos disposiciones (el preámbulo y el artículo 8) que configuran una norma legal contraria al artículo 2 de la Constitución.

\section{LA PRIVACIÓN DE EFICACIA JURÍDICA INTERPRETATIVA A LAS REFERENCIAS A LA NACIÓN Y A LA REALIDAD NACIONAL DE CATALUÑA}

Establecido lo anterior, está claro que las disposiciones del Preámbulo del Estatuto de Autonomía de Cataluña referidas a la «nación» y a la «realidad nacional» de Cataluña, a los «derechos históricos» como fundamento del autogobierno y al «derecho inalienable» al mismo, tienen un valor jurídico indiscutible. Y de ello se sigue que, si esas disposiciones conjuntamente con otras del texto articulado dan lugar a normas que resulten incompatibles con preceptos constitucionales, unas y otras deberían ser anuladas por el Tribunal Constitucional. 
Vamos a examinar en este epígrafe las dos primeras referencias preambulares citadas (Nación y realidad nacional) en la medida en que son las únicas sobre las que el Tribunal incluye un pronunciamiento expreso en el Fallo. En un epígrafe posterior analizaremos el pronunciamiento del Tribunal sobre los derechos históricos de Cataluña y sobre su derecho «inalienable» al autogobierno.

En la Sentencia que nos ocupa, el Tribunal consciente del valor normativo indirecto del Preámbulo, se ve obligado a analizar su contenido. Y al hacerlo va a comprobar que el significado y alcance de algunas de sus disposiciones (junto al de determinados artículos del texto estatutario) es susceptible de engendrar normas que no resultan compatibles con el artículo 2 de la Constitución.

Concretamente, y siguiendo el método de proceder a analizar el contenido de una disposición preambular al hilo del control de constitucionalidad de un artículo cuya interpretación exija del concurso de aquella, el Tribunal en el decisivo Fundamento Jurídico 12 analiza conjuntamente el artículo 8 del Estatuto relativo a los «símbolos nacionales» de Cataluña y la disposición preambular que establece: «El Parlamento de Cataluña, recogiendo el sentimiento y la voluntad de la ciudadanía de Cataluña, ha definido de forma ampliamente mayoritaria a Cataluña como nación. La Constitución española, en su artículo segundo, reconoce la realidad nacional de Cataluña como nacionalidad».

$\mathrm{El}$ art. $8 \mathrm{EAC}$ es objeto de impugnación por calificar como «nacionales» los símbolos de Cataluña relacionados en los distintos apartados del precepto. A juicio de los recurrentes, el calificativo remite de manera inequívoca a la nación catalana, incompatible, por contradictoria de su unidad e indivisibilidad, con la Nación española sobre la que se fundamenta la Constitución de acuerdo con el art. 2 CE. Tal remisión se vería confirmada, en opinión de los recurrentes, por la declaración incluida en el preámbulo acerca de la condición nacional de Cataluña proclamada en su momento por el Parlamento catalán.

En este contexto el Tribunal realiza una labor de clarificación conceptual notable. Y lo hace en estos términos:

«Es preciso convenir con el Abogado del Estado y con el Parlamento y la Generalitat de Cataluña en que el término «nación» es extraordinariamente proteico en razón de los muy distintos contextos en los que acostumbra a desenvolverse como una categoría conceptual perfectamente acabada y definida, dotada en cada uno de ellos de un significado propio e intransferible. De la nación puede, en efecto, hablarse como una realidad cultural, histórica, lingüística, sociológica y hasta religiosa. Pero la nación que aquí importa es única y exclusivamente la nación en sentido jurídico-constitucional. $Y$ en ese específico sentido la Constitución no conoce otra que la Nación española, con cuya mención arranca su preámbulo, en la que la Constitución se fundamenta (art. 2 CE) y con la que se cualifica expresamente la soberanía que, ejercida por el pueblo español como su único titular reconocido (art. 1.2), se ha manifestado como voluntad constituyente en los preceptos positivos de la Constitución Española»

Saliendo al paso de aquellas concepciones que sostienen que la Constitución vigente establece ya un Estado plurinacional, el Tribunal recuerda que la interpretación del artículo 2 no deja margen alguno para una tal comprensión del Estado como plurinacional por la razón evidente de que al Tribunal sólo le importa «la nación en sentido jurídico-constitucional. Y en ese específico sentido la Constitución no conoce otra que la Nación española». 
El Tribunal admite que el Estado nacional establecido en el artículo 2 puede ser transformado en Estado plurinacional mediante los procedimientos de reforma constitucional previstos en el Título correspondiente:

«En el contexto del Estado democrático instaurado por la Constitución, es obvio que, como tenemos reiterado, caben cuantas ideas quieran defenderse sin recurrir a la infracción de los procedimientos instaurados por el Ordenamiento para la formación de la voluntad general expresada en las leyes (por todas, STC 48/2003, de 12 de marzo). Y cabe, en particular, la defensa de concepciones ideológicas que, basadas en un determinado entendimiento de la realidad social, cultural y política, pretendan para una determinada colectividad la condición de comunidad nacional, incluso como principio desde el que procurar la conformación de una voluntad constitucionalmente legitimada para, mediando la oportuna e inexcusable reforma de la Constitución, traducir ese entendimiento en una realidad jurídica. En tanto, sin embargo, ello no ocurra, las normas del Ordenamiento no pueden desconocer ni inducir al equívoco en punto a la «indisoluble unidad de la Nación española» proclamada en el art. $2 \mathrm{CE}$, pues en ningún caso pueden reclamar para sí otra legitimidad que la que resulta de la Constitución proclamada por la voluntad de esa Nación, ni pueden tampoco, al amparo de una polisemia por completo irrelevante en el contexto jurídico-constitucional que para este Tribunal es el único que debe atender, referir el término «nación» a otro sujeto que no sea el pueblo titular de la soberanía».

Ahora bien, lo que no cabe es llevar a cabo esa transformación de la naturaleza del Estado — de nacional en plurinacional— mediante una Ley Orgánica.

El Tribunal, no obstante, va a salvar la constitucionalidad del adjetivo «nacionales» siempre que se entienda como propio de una «nacionalidad» y no de una Nación. Pero esa interpretación choca frontalmente con la disposición preambular que nos ocupa. Dicho de otra manera, la norma resultante de interpretar conjuntamente la disposición preambular y la contenida en el artículo 8 del Estatuto es contraria al artículo 2.

Por ser esto así, en nuestra opinión, el Tribunal estaba obligado como conclusión lógica de su propio razonamiento a anular la norma inconstitucional mediante la declaración de inconstitucionalidad y nulidad de las disposiciones preambulares y del adjetivo nacionales del artículo 8. Y sin embargo no lo hizo. El Tribunal reconstruyó el sentido del artículo 8 en términos constitucionales, y en contra del tenor literal, del sentido y propósito de sus redactores, dijo que «nacionales» no hace referencia a una nación. Esa reconstrucción le exigía inexorablemente prescindir del ineludible valor interpretativo que en relación con este precepto guarda la referencia del Preámbulo a la realidad nacional de Cataluña.

$\mathrm{Y}$ es así como concluye el decisivo Fundamento Jurídico 12 que ahora nos ocupa, privando de eficacia jurídica interpretativa a las referencias preambulares impugnadas:

«La referencia del art. 8 EAC a los símbolos nacionales de Cataluña podría inducir a esa indebida confusión si pretendieran extraerse de la mención del preámbulo a determinada declaración del Parlamento de Cataluña sobre la nación catalana unas consecuencias jurídico constitucionales contradictorias con el sentido preciso del art. 2 CE en punto a la sola y exclusiva relevancia constitucional de la Nación española. Sin embargo, cabe interpretar, de acuerdo con la Constitución, que con la calificación como «nacionales» de los simbolos de Cataluña se predica únicamente su condición de simbolos de una nacionalidad consti- 
tuida como Comunidad Autónoma en ejercicio del derecho que reconoce y garantiza el art. 2 $\mathrm{CE}$, pues así expresamente se proclama en el art. 1 EAC y se reitera en el art. 8 EAC. Se trata, en suma, de los símbolos propios de una nacionalidad, sin pretensión, por ello, de competencia o contradicción con los símbolos de la Nación española.

En atención al sentido terminante del art. 2 CE ha de quedar, pues, desprovista de alcance jurídico interpretativo la referida mención del preámbulo a la realidad nacional de Cataluña y a la declaración del Parlamento de Cataluña sobre la nación catalana, sin perjuicio de que en cualquier contexto que no sea el jurídico-constitucional la autorepresentación de una colectividad como una realidad nacional en sentido ideológico, histórico o cultural tenga plena cabida en el Ordenamiento democrático como expresión de una idea perfectamente legítima.

Por todo ello, los términos «nación» y «realidad nacional» referidos a Cataluña, utilizados en el preámbulo, carecen de eficacia jurídica interpretativa, lo que dada la especial significación de un preámbulo estatutario así se dispondrá en el fallo; y el término «nacionales» del art. 8.1 EAC es conforme con la Constitución interpretado en el sentido de que dicho término está exclusivamente referido, en su significado y utilización, a los símbolos de Cataluña, «definida como nacionalidad» (art. 1 EAC) e integrada en la «indisoluble unidad de la nación española» como establece el art. 2 CE, y así se dispondrá en el fallo».

Este importante pronunciamiento, que no olvidemos constituye el objeto del primer párrafo del fallo, es susceptible de dos tipos de análisis. Un análisis material consistente en valorar la corrección del juicio de inconstitucionalidad de una norma que atribuya el carácter de «nación» en sentido jurídico constitucional a Cataluña (3.1). Y un análisis formal sobre la coherencia de la fórmula empleada para garantizar la supremacía normativa del artículo 2 CE (3.2).

\section{III.1. LA INTERPRETACIÓN DEL ARTÍCULO 2 CE}

Empezando con el primer análisis, debemos subrayar que el propósito de las disposiciones preambulares impugnadas (las que incluyen los conceptos de «nación» y «realidad nacional» aplicadas a Cataluña) es meridianamente claro. De una u otra forma se pretende atribuir un concreto significado al término nacionalidad contenido en el artículo 2 de la Constitución. Se pretende establecer en un texto legal el significado de un precepto constitucional. Y ello explicitando que cuando el artículo 2 de la Constitución habla de «nacionalidades», al menos para Cataluña, lo que está diciendo es que dicha Comunidad constituye una realidad nacional. Y ese reconocimiento es el que explica después el significado y alcance de muchas disposiciones del texto articulado, y no sólo del artículo 8 como parece entender el Tribunal (desde las relativas al blindaje de las competencias autonómicas, pasando por la asunción de competencias en materias como Justicia o Relaciones Internacionales, hasta el establecimiento de un sistema de relaciones bilaterales con el Estado).

En todo caso, en nuestra opinión, en la argumentación del Alto Tribunal subyace un correcto entendimiento de los términos nación y nacionalidad contenidos en el artículo 2 que creo oportuno exponer. Y ello porque el Tribunal ha recibido ya numerosas críticas en sede política y mediática por el simple hecho de haber reconocido algo que para 
muchos es evidente: en términos jurídico-constitucionales no hay más nación que la española. Y el término nacionalidad en modo alguno puede entenderse como sinónimo de nación o realidad nacional en sentido jurídico-político.

Como es sabido, la inclusión del término «nacionalidades» en el artículo 2 de la Constitución española de 1978 distó mucho de ser una cuestión pacífica.

Múltiples fueron las críticas al empleo de ese término. En primer lugar, se alegó la improcedencia de utilizarlo como sustantivo en la medida en que nacionalidad sería un atributo o cualidad de la nación, pero no una realidad diferente de ella. Por otro lado, se sostuvo que la utilización del vocablo nacionalidad en el artículo 2 oscurecía el verdadero significado del mismo en el artículo 11, referido al status jurídico de los ciudadanos españoles. En tercer lugar, y tal fue la crítica del diputado y profesor, Manuel Fraga, se advirtió que con independencia de cuál fuera la voluntad del constituyente, el término podría servir en el futuro para reclamar «la aplicación del llamado principio de las nacionalidades, con las inevitables consecuencias de un pretendido derecho a la autodeterminación y a un Estado propio». Por último, se denunció la posibilidad de que el término sirviera para establecer una jerarquía entre las distintas Comunidades Autónomas, en función de su cualificación como nacionalidad o como región.

No es este el lugar para analizar el significado que el término nacionalidad revistió tanto en el derecho constitucional comparado como en nuestra literatura jurídica y política. Lo que nos interesa es, por un lado, precisar cuáles fueron las razones que llevaron a nuestro constituyente a la inclusión del término en el Texto Fundamental; y, por otro, determinar cuál fue el concreto significado y el verdadero alcance que se le atribuyó. En este sentido, podemos afirmar que las razones fueron únicamente de oportunidad política y los perfiles del término resultaron bastante claros.

En relación con la primera de las cuestiones mencionadas, debemos al profesor Tierno una observación fundamental. La relativa a la verdadera utilidad o rentabilidad política de la inclusión del término «nacionalidad» en el artículo 2. Para Tierno Galván, se trataba de la contrapartida exigida por los nacionalismos periféricos para el abandono de sus pretensiones separatistas, soberanistas y autodeterministas. Así, se trataría «de un compromiso para evitar que las regiones o nacionalidades rompieran definitivamente con el depósito permanente y unitario de España».

Por esta razón, y a pesar de las reticencias y objeciones que el término planteaba ${ }^{6}$, en aras a posibilitar la integración en la España constitucional de aquellas comunidades que no se sentían cómodas hasta entonces con su encaje en el Estado, el constituyente decide incorporar el término «nacionalidad» con un significado muy claro. En palabras del profesor Solozábal, uno de los más lúcidos estudiosos de la problemática que nos ocupa, por nacionalidad entendemos «aquella comunidad con conciencia de su especificidad histórica-cultural y dotada de una cierta vocación política» ${ }^{7}$.

6 Entre ellas la muy autorizada del maestro GARCíA-PELAYO, quien advirtió del riesgo de que la inclusión del término nacionalidades implicase la creación de privilegios o discriminaciones entre las Comunidades o pudiera tener perniciosos e imprevistos efectos, toda vez que, por encima de su carácter semántico, «en política lo semántico puede tener mucha importancia, pues (...) los vocablos no sólo designan cosas, sino que son también consignas y banderines para la acción: no solamente abstraen ciertas realidades, sino que contribuyen a agrupar a las gentes en partidarios y adversarios». Entrevista publicada en EL PAIS, 1 de febrero de 1977, y recogida en García Pelayo, M.: Obras Completas, CEC, Madrid, 1993, vol. III, pág. 3265.

7 SOlOZÁBAL, J. J.: «Nación, nacionalidades y Autonomías en la Constitución de 1978», en Las bases constitucionales del Estado Autonómico, Mc Graw-Hill, Madrid, 1998, pág. 81. 
La definición constitucional de España como una unidad superior de nacionalidades y regiones supuso el rechazo expreso a configurarla como nación de naciones. En la Constitución de 1978, la nacionalidad no es sinónimo de nación política sino de región con acusada conciencia de su especificidad, lo que podemos denominar como nación cultural. En definitiva, como concluye el profesor Corcuera, «el término de «nacionalidades» acaba definiéndose en el terreno de aquellas naciones «histórico-culturales» distintas a la «nación-Estado» según la definición que se atribuye a Meinecke, a cuya definición se incorpora normalmente un ingrediente voluntarista o de conciencia de diferencia específica» ${ }^{8}$. Ahora bien, la Constitución no enumera ni define los criterios en virtud de los cuales una Comunidad Autónoma deba ser cualificada como nacionalidad o como región.

Una vez expuestas las razones que determinaron la inclusión del término nacionalidad en el artículo 2 de la Constitución, debemos examinar las consecuencias jurídicas que de ello se derivan. Tres son las cuestiones que, desde esta perspectiva, hay que subrayar. a) En primer lugar, que el constituyente rechazó de forma expresa la atribución a las nacionalidades del derecho de autodeterminación. El poder constituyente soberano reside exclusivamente en el pueblo español. A las nacionalidades se les reconoce y garantiza el derecho a la autonomía que es un poder limitado y constituido. b) En segundo lugar, que, privado el concepto de nacionalidad de su dimensión política convencional, (según la cual, la autodeterminación, esto es, la consecución del propio estado es el corolario del principio de las nacionalidades), resulta que su contenido es eminentemente cultural. Las nacionalidades se identifican así con lo que algunos han denominado naciones culturales o naciones en sentido cultural frente a las naciones políticas. c) En tercer lugar, que de la distinción entre nacionalidades y regiones no es lícito deducir posiciones singulares o privilegiadas de unas respecto a otras. Entre otras cosas porque jurídicamente nada impide que las 17 Comunidades Autónomas se definan como nacionalidades.

En definitiva, que el significado del término «nacionalidad» contenido en el artículo $2 \mathrm{CE}$ es claro, en cuanto que se identifica con «nación cultural». De esa manera, se excluye la posible consideración de una Comunidad Autónoma como «nación política». Nación política en el Estado configurado por el Constituyente de 1977-78 no hay más que una: España.

A la luz de todo lo que acabamos de exponer, si confrontamos el artículo 2 CE con las disposiciones preambulares del Estatuto de Cataluña y con el artículo 8 del mismo, comprobamos que existe una clara contradicción. Contradicción que el Tribunal no puede desconocer y que pone de manifiesto con meridiana claridad y acierto pleno en el Fundamento Jurídco 12 antes transcrito.

En este contexto el interrogante al que inevitablemente tiene que dar respuesta el Tribunal es el siguiente: ¿Qué significa el término «realidad nacional» incluido en el Preámbulo?. Para ello basta acudir al proceso de elaboración del Estatuto. De los debates estatuyentes se deduce con total claridad que realidad nacional es sinónimo de nación (nación política) y no de nacionalidad (nación cultural). Ello quiere decir que el legislador orgánico está atribuyendo al término nacionalidad un significado, no sólo distinto, sino incompatible con el que le atribuyó el constituyente.

8 CORCUERA, J.: «La distinción constitucional entre nacionalidades y regiones en el décimoquinto aniversario de la Constitución», en Documentación Administrativa, núm. 232-233, 1992-93, pág. 18. 
El Tribunal Constitucional no puede aceptar que el legislador orgánico modifique el significado y alcance del artículo $2 \mathrm{CE}$. Y en él es evidente que nacionalidad no es sinónimo de nación política. Por el contrario, a ese entendimiento conduce una lectura conjunta del Preámbulo y el articulado del Texto estatutario. Sólo por ello queda justificada plenamente la privación de eficacia interpretativa alguna a esas referencias.

Cuando el Estatuto de Cataluña hace referencia a su condición de «realidad nacional» (reconocida por el Parlamento) lo que está queriendo decir (basta acudir a los debates correspondientes) es que Cataluña es una nación, y no sólo una nacionalidad. Para decir que son naciones en su dimensión cultural aquel reconocimiento sobraba por innecesario. El término nacionalidad basta para cumplir ese fin. Ahora bien, ese reconocimiento solo tiene sentido y virtualidad si lo que se está afirmando con el término «realidad nacional» es que son naciones en el sentido político del término. Y esa afirmación por parte del legislador estatuyente resulta constitucionalmente inaceptable.

Ahora bien, en la medida en que la disposición preambular por sí sola no engendra una norma jurídica no resultaría preciso anularla. El problema surge cuando de su interpretación conjunta con otra disposición del articulado surge la norma legal inconstitucional. Y así ocurre con el artículo 8.

Al Tribunal no le basta el débil argumento de que el Preámbulo se limita a recoger declaraciones o afirmaciones de terceros (el Parlamento de Cataluña) y que por ello carece de relevancia. El Preámbulo lo es de una Ley Orgánica. Lo que se trata es de ver si la interpretación de determinados artículos del Estatuto derivada y exigida por esas declaraciones resulta compatible o no con la Constitución. Dicho con otras palabras, el Tribunal debe examinar si las declaraciones preambulares conjuntamente a otras disposiciones articuladas han dado lugar a normas inconstitucionales. Si lo han hecho, resulta evidente que esos pronunciamientos (de indiscutible eficacia interpretativa) no pueden ser recogidos por el legislador orgánico en un texto que reviste precisamente el carácter de Ley Orgánica, y cuyo valor normativo (indirecto) es indiscutible.

\section{III.2. LA ARTIFICIOSA FRAGMENTACIÓN DE LA NORMA INCONSTITUCIONAL (FJ 12)}

Expuesto así el razonamiento del Tribunal, que como hemos dicho resulta jurídicamente impecable, procede examinar el expediente arbitrado para garantizar la supremacía normativa del artículo $2 \mathrm{CE}$. Y ello porque se basa en un artificio falto de rigor y de coherencia y del que puede incluso dudarse - tal y como advierten los magistrados discrepantes - sobre su efectividad.

A estas alturas de la exposición, y combinando lo expuesto en los dos epígrafes anteriores, resulta sencillo de concluir que si el Tribunal ha detectado una norma inconstitucional, y que dicha norma resulta de la interpretación conjunta de una disposición preambular y de un término del articulado, su obligación es proceder a la anulación de dicha norma inconstitucional. E igualmente evidente resulta que si esa norma es compleja, esto es, está integrada por dos disposiciones, la declaración de inconstitucionalidad de la norma indudablemente conlleva la nulidad de las dos disposiciones (preambular y articulada).

Y sin embargo, no es esto lo que hace el Tribunal. El Tribunal, asombrosamente, evita anular las dos disposiciones: 
a) Para evitar la anulación del adjetivo «nacionales» contenido en el artículo 8, el Tribunal realiza una interpretación del mismo conforme a la Constitución que implica la alteración de su literalidad y propósito. El adjetivo es constitucional si se entiende como propio de una «nacionalidad» y no de una nación. A esta fórmula cabe realizar la crítica general que la sentencia merece en cuanto a los excesos que comete el Tribunal al hacer decir al Estatuto en muchas ocasiones lo contrario de lo que expresamente afirma?

b) Ahora bien, la interpretación anterior no solo chocaba con la literalidad del término y con el propósito de sus redactores, sino que resultaba jurídicamente incompatible con la previsión preambular de que «la Constitución española, en su artículo segundo, reconoce la realidad nacional de Cataluña como nacionalidad». Si nacionalidad era la fórmula que definía a una «realidad nacional», el símbolo nacional, siéndolo de la nacionalidad, en realidad lo es de la «nación», esto es, justamente lo que el Tribunal rechaza.

En definitiva, la interpretación del artículo 8 efectuada por el Tribunal Constitucional era completamente opuesta a la interpretación que venía exigida por el Preámbulo del Estatuto. Sólo por ello, dicha interpretación debe considerarse artificiosa, arbitraria, y carente de todo fundamento y apoyo. Responde al único propósito de evitar la declaración de su nulidad.

En este contexto, y para poder imponer su peculiar interpretación conforme del artículo 8 en el apartado segundo del Fallo, el Tribunal en el apartado primero se ve obligado a introducir el pronunciamiento que nos ocupa: «carecen de eficacia jurídica interpretativa las referencias del Preámbulo del Estatuto de Cataluña a "Cataluña como nación" y a "la realidad nacional de Cataluña"».

Mediante este doble y artificioso expediente es preciso reconocer que el Tribunal cumple su función de defensa de la Constitución y salvaguarda la supremacía normativa del artículo 2. La transformación del Estado Constitucional vigente en un Estado plurinacional es una operación vedada al legislador orgánico y reservada al poder constituyente constituido (poder de reforma).

Ahora bien, si el resultado jurídico-político alcanzado es encomiable, no podemos dejar de criticar el método empleado. No sólo por lo que de arbitrario tiene la interpretación del artículo 8, sino también por la inseguridad jurídica que provoca la no anulación de los preceptos preambulares impugnados.

Desde el punto de vista de la más correcta técnica jurídica y tal y como sostienen algunos magistrados discrepantes en sus votos particulares, el Tribunal debiera haber

9 Así lo ha denunciado también Blanco VALDÉs en uno de los más lúcidos comentarios de la sentencia realizados hasta la fecha. «El Tribunal da aquí un nuevo quiebro por virtud del cual las palabras significan para él algo diferente de lo que significan según el Diccionario de la Lengua Española. Y es que, mientras que... el alto Tribunal parte de un principio inimpugnable (el de que, en sentido jurídico-constitucional, «la Constitución no conoce otra nación que la española»), lo cierto es que luego se niega a sacar la consecuencia lógica que de ello debería derivarse, anulando los preceptos que predican para Cataluña una naturaleza de la que jurídicoconstitucionalmente carece porque en tal ámbito no puede poseerla. Lejos de ello, el Tribunal retuerce de nuevo las palabras para cohonestar con la Constitución lo que sin tal retorcimiento sería incohonestable... Su afirmación es una mera petición de principios que carece de la más mínima base, pues nacional (o su plural, nacionales) es según el Diccionario «lo perteneciente o relativo a una nación». Y dado que Cataluña no lo es, jurídicamente, mal puede tener símbolos nacionales quien carece de la naturaleza de nación. Pero nada de eso importa: los símbolos nacionales de Cataluña lo son de una nacionalidad porque así lo afirma gratuitamente el Tribunal, aunque lo nacional sea, como muy bien sabían quienes impulsaron la norma estatutaria, lo relativo o perteneciente a una nación», BLANCO VALDÉS, R.: «El Estatuto catalán y la sentencia de nunca acabar», en Claves de Razón Práctica, n 205 , septiembre, 2010, págs. 10-11. 
procedido a la declaración de inconstitucionalidad y nulidad de las disposiciones preambulares impugnadas. Y ello porque carece por completo de sentido mantener la validez formal de unas disposiciones carentes de eficacia alguna. En realidad, y como bien sostienen los magistrados discrepantes, las razones por las cuáles la mayoría del Tribunal decide privar a dichas referencias de eficacia jurídica interpretativa, no solo justifican sino que exigen por su relevancia, su anulación.

Además, el artificio que denunciamos implica la fragmentación de la norma cuya inconstitucionalidad se ha detectado. El adjetivo «nacionales» formalmente no invalidado se ha conservado al precio de desvincularlo de la interpretación que el propio Estatuto hacía del mismo en su Preámbulo. Y esa desvinculación no resulta de la anulación de las disposiciones del Preámbulo como hubiera resultado lógico, sino de la «privación de eficacia jurídica interpretativa» de esas disposiciones. El Tribunal priva al Preámbulo de su función pero conserva su existencia. Con ello asesta un duro golpe al principio de seguridad jurídica que es advertido con acierto por los votos particulares discrepantes. Si esas disposiciones preambulares no tienen eficacia jurídica interpretativa, ¿qué valor o efectos conservan?

La inseguridad jurídica se incrementa por el hecho de que la declaración del párrafo primero del fallo se limita a privar de eficacia jurídica interpretativa a los términos nación y realidad nacional, pero no se lleva al fallo la interpretación conforme de otras disposiciones preambulares que también son susceptibles por su valor normativo indirecto de generar -interpretadas conjuntamente con otros artículos - normas estatutarias inconstitucionales. Una lectura atenta de la sentencia nos confirma que también carecen de eficacia jurídica interpretativa las referencias a los derechos históricos y al derecho inalienable al autogobierno, tal y como figuran en el Preámbulo. Sin embargho, el Fallo omite cualquier pronunciamiento al respecto.

En nuestra opinión que es coincidinte con la de los magistrados disidentes, todos estos problemas podían y debían haberse evitado mediante la declaración de nulidad de las disposiciones preambulares impugnadas.

La mera existencia del Preámbulo se configura como un arma política susceptible todavía de producir algún tipo de efecto jurídico ${ }^{10}$. El Tribunal debió desactivarla. Y, no por razones políticas, sino por razones derivadas de la lógica jurídica anteriormente expuesta. Sin embargo, la mayoría del Tribunal, por razones de oportunidad política, prefirió optar por un expediente que formalmente evitara la anulación de las disposiciones impugnadas. Ello sólo fue posible mediante el artificio que hemos criticado. Artificio que si jurídicamente resulta rechazable, políticamente no sirvió para evitar críticas de tan grueso calibre como escaso fundamento, según las cuales el Tribunal ha ofendido a Cataluña y a los sentimientos de los catalanes. El recordatorio de que en sentido jurídicoconstitucional (no en otros ámbitos, culturales o ideológicos) sólo existe la nación española fue considerado por algunos una ofensa gratuita.

10 Que como advierte acertadamente Blanco podría ser esgrimida en el ambito del Derecho Internacional. «En el plano del Derecho Internacional — mucho más relevante sin duda para los impulsores del texto. Es igualmente difícil de imaginar que el fallo del Tribunal pueda privar de potencialidad reivindicativa a una norma de derecho interno que dispone, sin que el Tribunal lo haya anulado, que Cataluña es una nación y que tiene símbolos nacionales». BLANCO VALDÉS, R.: «El Estatuto catalán..., ob. cit., pág. 11. 


\section{EL PRONUNCIAMIENTO DEL TRIBUNAL SOBRE LOS «DERECHOS HISTÓRICOS» DE CATALUÑA}

En relación con los «derechos históricos de Cataluña» el Tribunal ha hecho un pronunciamiento que salva su constitucionalidad (en el Preámbulo y en el artículo 5 del Estatuto) mediante la interpretación de aquellos en contra de su tenor literal y de su significado evidente. Con ello el Tribunal ha obrado una vez más movido por razones de oportunidad y ha quebrado la lógica jurídica. Pero, sobre todo, ha desaprovechado la oportunidad de desactivar un historicismo que es incompatible con cualquier concepción moderna, racional y eficaz de la organización territorial del poder ${ }^{11}$. Los magistrados discrepantes, por el contrario, han interpretado correctamente las disposiciones impugnadas y han concluido en la necesidad de anularlas.

\section{IV.1. El FORTALECIMIENTO DEL HISTORICISMO EN EL NUEVO ESTATUTO DE Cataluña}

Además de haber logrado un privilegiado sistema de financiación para la Comunidad Autónoma Vasca y para la Comunidad Foral de Navarra (distinto del general o común aplicable a las otras 15 Comunidades Autónomas), el reconocimiento constitucional (en la DAP) de los derechos históricos ha servido al nacionalismo vasco (y a ciertos sectores del foralismo navarro) para tratar de consolidar la no por falsa menos peligrosa idea de que la autonomía vasca (y la navarra para los juristas forales) se fundamenta en un título diferente a la Constitución. Esto es que la fuente de legitimidad es otra distinta del sujeto constituyente (el Pueblo español).

Lo que resulta sumamente preocupante, aunque es perfectamente comprensible e incluso previsible, es que el lenguaje historicista empleado por los estatuyentes vasco y navarro haya sido adoptado por la mayor parte de los estatuyentes durante el proceso de reformas estatutarias llevado a cabo durante la VIII Legislatura. Junto al relato mágico consistente en idealizar el régimen político foral como un antiguo escenario de libertad y de armonía entre todos los vascos (o entre todos los navarros) tenemos ahora numerosos relatos sobre la Historia de infinidad de pueblos peninsulares que llevan siglos luchando por la libertad y por la igualdad y unidos por profundos lazos de solidaridad colectiva. Los Preámbulos de los nuevos Estatutos han sido el lugar de acogida de estas narraciones míticas.

Este fenómeno es preocupante en la medida en que el principio de legitimidad histórica, inicialmente introducido por el Constituyente (DAP) con un carácter excepcional, se expande ilimitadamente. Ya no son sólo el País Vasco y Navarra los que buscan fundamentar o legitimar su autonomía en títulos distintos a la voluntad del pueblo español, sino que lo mismo pretende, Cataluña. Así se desprende de la disposición preambular y del artículo 5 del Estatuto. Se trata de un proceso perfectamente previsible en

11 Sobre la problemática general que plantea, desde la lógica de la Constitución normativa, la categoría de Derechos Históricos, remito al lector a TAJADURA, J.: «Constitución y Derechos Históricos: Legitimidad democrática frente a legitimidad histórica», en Teoría y Realidad Constitucional, no 22, 2008, págs. 137-192. 
la medida en que al haberse percatado el resto de las Comunidades Autónomas de la ventajosa situación de Navarra y del País Vasco y de que esa situación obedece a un privilegiado sistema de financiación cuyo fundamento no es otro que la Historia, nada de extraño tiene que aquellas quieran apelar también a la Historia. Dicho con otras palabras, la apelación a la legitimidad histórica ha permitido a dos Comunidades Autónomas disfrutar de unos privilegios, o, aun concediendo que no sea un privilegio, de un singular sistema de financiación ${ }^{12}$. Es lógico que aquellos que pretenden disfrutar del mismo recurran por tanto, también, al discurso historicista.

La legitimación de las diferencias entre Comunidades en virtud de la Historia ha sido una constante en la evolución del Estado Autonómico y ha sido la causa de su fracaso en el empeño de consolidarse como un Estado Federal basado en el insoslayable principio de igualdad entre sus miembros. Desde esta perspectiva, y ese es otro de sus perturbadores efectos sobre el sistema, la DAP impide consolidar nuestro Estado Autonómico como Estado Federal. De hecho, introduce el principio confederal (pactista) para las dos Comunidades titulares de Derechos Históricos y de esta forma, ha producido una sensación de agravio en el resto de Comunidades, generadora de una espiral reivindicativa cuya traducción son los nuevos Estatutos de Autonomía (Valencia, Cataluña, Andalucía y otros). Los rasgos confederales del modelo de Estado resultante de los nuevos Estatutos han sido denunciados por la mejor doctrina (MUÑOz MACHAdO, SOSA WAGNER).

«Una mirada al desarrollo constitucional — escribe con meridiana claridad y acierto pleno Tudela Aranda - y más con los textos de reforma estatutaria encima de la mesa, lleva a la conclusión nítida de que la concepción racionalista ha sido incapaz no ya de ganar la batalla, sino, al menos de establecer unas coordenadas mínimas. La interpretación historicista ha ganado adeptos en cuanto ha permitido la consecución paulatina de mayor autonomía. Y sobre todo, en cuanto se vislumbra como fuente inacabable cuantitativa y cualitativamente para la reivindicación territorial. En este sentido, la aparición del pueblo como sujeto colectivo de derechos y heredero de toda una historia de grandeza y agravios es la mejor expresión de la debilidad racionalista frente al historicismo» ${ }^{13}$.

El historicismo ha sido reforzado en el nuevo Estatuto de Cataluña con cláusulas de dudoso encaje constitucional y finalidad claramente antidemocrática. Y ello porque aunque el historicismo puede tener muy distintos significados, como bien advirtió —en estas mismas páginas - el profesor Francesc de Carreras durante la fase de elaboración del nuevo Estatuto catalán: «El historicismo considerado como el fundamento de instituciones políticas únicamente ha sido utilizado con una finalidad: eliminar, frenar o limitar la voluntad popular, el poder del pueblo, la capacidad de decisión de los ciudadanos. En definitiva, para impedir el ejercicio de los derechos democráticos» ${ }^{14}$.

12 Si es un sistema singular y no generalizable, esto es, una facultad que unos disfrutan y otros no podrán hacerlo nunca, y ello sin ninguna razón que justifique ese diferente trato (salvo que la apelación a la Historia pueda ser considerada en el siglo XXI como una razón justificadora de una diferencia tan importante) desde una perspectiva jurídica es más correcto denominarlo "privilegio». Ahora bien, esta categoría sí que está expresamente prohibida por la Constitución que en su art. 138 establece que las diferencias entre Estatutos no podrán implicar privilegios.

13 Tudela Aranda, J.: «La Disposición Adicional Primera y los nuevos Estatutos de Autonomía. La Historia como legitimación de la Autonomía», en Revista de Administración Pública, no 173, 2007, pág. 166.

14 CARRERAS, DE F.: «Reflexiones sobre la propuesta de nuevo Estatuto de Cataluña», en Teoría y Realidad Constitucional, ñ 16,2005 , pág. 64. 
El Estatuto de Autonomía de Cataluña, contiene dos importantes alusiones a los derechos históricos (Preámbulo y artículo 5). Las dos han sido impugnadas y, lamentablemente, ninguna de ellas ha sido anulada por el Tribunal Constitucional.

\section{IV.2. LA INTERPRETACIÓN CONFORME A LA CONSTITUCIÓN DE LOS DERECHOS HISTÓRICOS DE CATALUÑA. (FJ. 10)}

El Preámbulo del nuevo Estatuto coloca en pie de igualdad a la Constitución y a los derechos históricos del pueblo catalán, como fundamento de un autogobierno «singular»: «El autogobierno de Cataluña se fundamenta en la Constitución, así como en los derechos históricos del pueblo catalán que, en el marco de aquella, dan origen en este Estatuto al reconocimiento de una posición singular de la Generalidad». Fácilmente se ve aquí, una vez más, la apelación a la historia para justificar la diferencia ${ }^{15}$.

El historicismo del Preámbulo se proyecta sobre todo el articulado, pero de forma especial, encuentra su plasmación en el —a mi juicio, inconstitucional—artículo 5: «El autogobierno de Cataluña se fundamenta también en los derechos bistóricos del pueblo catalán, en sus instituciones seculares y en la tradición jurídica catalana, que el presente Estatuto incorpora y actualiza al amparo del artículo 2, la disposición transitoria segunda y otros preceptos de la Constitución, de los que deriva el reconocimiento de una posición singular de la Generalitat en relación con el derecho civil, la lengua, la cultura, la proyección de éstas en el ámbito educativo, y el sistema institucional en que se organiza la Generalitat».

El pronunciamiento del Tribunal resulta sorprendente. Se basa en dos premisas, una de las cuáles es rotundamente falsa y otra sumamente confusa:

a) «El art. 5 EAC — dice el Tribunal- sería manifiestamente inconstitucional si pretendiera para el Estatuto de Autonomía un fundamento ajeno a la Constitución, aun cuando fuera añadido al que ésta le dispensa. Sin embargo, el enunciado íntegro del artículo permite descartar esa interpretación...». Resulta más que evidente que el significado del «así como» y de «también» aplicado a los derechos históricos no puede ser otro que el de considerar estos como un fundamento del Estatuto y del autogobierno añadido al único constitucionalmente aceptable: la propia Constitución. Y de la misma forma, de dichos términos se deriva que ambos fundamentos se colocan en pie de igualdad ${ }^{16}$. Esa y no otra es la única pretensión que cabe deducir del Estatuto por más que el Tribunal lo niegue. La afirmación que hace el Tribunal es rotundamente falsa. La cierta es justamente la contraria ${ }^{17}$.

15 En este Preámbulo, el legislador estatuyente insiste en el fundamento histórico del autogobierno al afirmar que «la libertad colectiva de Cataluña encuentra en las instituciones de la Generalitat el nexo con una historia de afirmación y respeto de los derechos fundamentales y de las libertades públicas de la persona y de los pueblos; historia que los hombres y mujeres quieren proseguir».

16 Así lo advierte también BLANCO: «El Estatuto proclama, en suma, un principio de doble legitimidad (La Constitución y los derechos históricos del pueblo catalán) algo que según el Tribunal sería manifiestamente inconstitucional de no ser porque según la sentencia, el precepto no dice lo que, tras su lectura, todo el mundo puede interpretar que afirma con toda claridad». BLANCO VALDÉs, R.: «El Estatuto catalán..., ob. cit., pág. 10.

17 Directa relación con este tema guarda la impugnación del art. 2. 4 del Estatuto: los poderes de la Generalitat emanan del pueblo de Cataluña. Aquí también se establece un fundamento añadido al autogobierno, y por la misma razón, debería considerarse inconstitucional. Sin embargo, para el Tribunal el propósito de este precepto es «hacer de la legitimación democrática el principio que ha de regir el ejercicio por la Comunidad Autónoma de los poderes que el Estatuto de Autonomía le confiere desde la Constitución». Por ello y en con- 
b) El Tribunal considera también descartable que con estas referencias a los derechos históricos «se hayan querido traer a colación para la Comunidad Autónoma de Cataluña los derechos históricos a los que se refiere la disposición adicional primera de la Constitución. Tanto los derechos históricos como las instituciones seculares y la tradición jurídica de Cataluña invocados por el precepto son únicamente aquellos «de los que deriva el reconocimiento de una posición singular de la Generalitat en relación con el derecho civil, la lengua, la cultura, la proyección de éstas en el ámbito educativo, y el sistema institucional en que se organiza la Generalitat», según concluye el propio art. 5 EAC. Se trata, pues, de derechos históricos en un sentido bien distinto del que corresponde a los derechos de los territorios forales a que se refiere la disposición adicional primera de la Constitución. Y ello porque se refieren a derechos y tradiciones de Derecho privado o, en el ámbito del Derecho público, al derecho que la disposición transitoria segunda de la Constitución ha querido atribuir a los territorios que en el pasado hubieran plebiscitado Estatutos de autonomía en orden a facilitarles su constitución como Comunidades Autónomas a través de un procedimiento específico. Con ese limitado alcance, por completo diferente al que la Constitución ha reconocido a los derechos de los territorios forales de la disposición adicional primera, el art. 5 EAC anticipa el elenco de competencias que, de acuerdo con la Constitución, atribuye a la Comunidad Autónoma en el ámbito de la lengua, de la cultura y de la educación y hace explícitas las razones que justifican el concreto sistema institucional en el que se organiza la Generalitat de Cataluña».

Con estas premisas, el Tribunal declara la constitucionalidad de las disposiciones impugnadas. Observese que la interpretación que el Tribunal considera inconstitucional es justamente la única que cabe hacer dada la literalidad de los términos empleados (así como y también). Por el contrario, la interpretación conforme, por un lado, implica la alteración de aquellos términos, y por otro, introduce la confusión y una vez mas, la inseguridad jurídica, al aceptar la inclusión en el bloque de la constitucionalidad de unos derechos históricos distintos de los previstos en la DAP, y cuyas consecuencias futuras resultan obviamente inciertas.

«Sólo de manera impropia — concluye el Tribunal— podría entenderse que tales derechos históricos son también, jurídicamente, fundamento del autogobierno de Cataluña, pues en su expresado alcance constitucional únicamente pueden explicar la asunción estatutaria de determinadas competencias en el marco de la Constitución, pero nunca el fundamento de la existencia en Derecho de la Comunidad Autónoma de Cataluña y de su derecho constitucional al autogobierno. Los derechos, instituciones y tradiciones aludidos en el precepto, lejos de fundamentar en sentido propio el autogobierno de Cataluña, derivan su relevancia constitucional del hecho de su asunción por la Constitución y, des-

tra de lo que el tenor del precepto parece indicar, «El pueblo de Cataluña no es, por tanto, en el art. 2.4 EAC, sujeto jurídico que entre en competencia con el titular de la soberanía nacional cuyo ejercicio ha permitido la instauración de la Constitución de la que trae causa el Estatuto que ha de regir como norma institucional básica de la Comunidad Autónoma de Cataluña. El pueblo de Cataluña comprende así el conjunto de los ciudadanos españoles que han de ser destinatarios de las normas, disposiciones y actos en que se traduzca el ejercicio del poder público constituido en Generalitat de Cataluña. Justamente por ser destinatarios de los mandatos de ese poder público, el principio constitucional democrático impone que también participen, por los cauces constitucional y estatutariamente previstos, en la formación de la voluntad de los poderes de la Generalitat. Tal es el designio que justifica la expresión «pueblo de Cataluña» en el art. 2.4 EAC, por entero distinta, conceptualmente, de la que se significa en nuestro Ordenamiento con la expresión "pueblo español», único titular de la soberanía nacional que está en el origen de la Constitución y de cuantas normas derivan de ella su validez. Así entendido ha de desestimarse la impugnación del art. 2.4 EAC». 
de ella, fundamentan, en términos constitucionales, el sistema institucional y competencial instaurado con el Estatuto de Autonomía.

En definitiva, el art. 5 EAC no es contrario a la Constitución interpretado en el sentido de que su inciso «en los derechos históricos del pueblo catalán» no remite al contenido de la disposición adicional primera de la Constitución ni es fundamento jurídico propio del autogobierno de Cataluña al margen de la Constitución misma, y así se dispondrá en el fallo.

En los mismos términos ha de entenderse la afirmación del preámbulo de que «[e]l autogobierno de Cataluña se fundamenta en la Constitución así como en los derechos históricos del pueblo catalán que, en el marco de aquélla, dan origen en este Estatuto al reconocimiento de una posición singular de la Generalitat».

Insisto en que el razonamiento del Tribunal es inaceptable por razones puramente gramaticales. La lectura conjunta del Preámbulo, y del artículo quinto del Estatuto de Cataluña pone claramente de manifiesto que en él se recoge el principio de doble legitimidad de la autonomía de Cataluña. El artículo 5 dice expresamente «también» y la disposición preambular «así como». La consideración de los derechos históricos como un fundamento añadido es indiscutible. Y la fundamentación de la autonomía catalana en un título distinto a la Constitución democrática es incompatible con esta. Las disposiciones impugnadas son por ello contrarias a la Constitución, y el Tribunal debió anularlas tal y como sostienen los magistrados discrepantes.

Haciendo abstracción de lo anterior, es cierto que la referencia a la "posición singular» es susceptible de dos lecturas. Una estricta, en virtud de la cual la singularidad catalana se circunscribe a un régimen especial respecto a las concretas materias en él referidas. Y otra más amplia, que como apunta Tudela Aranda «vincularía la posición especial en esas materias con los preceptos constitucionales, mientras que los derechos históricos podrían servir para un juego más amplio, fundamentador de un futuro y más ambicioso régimen de autogobierno ${ }^{18}$. En nuestra opinión, la finalidad del precepto se corresponde con esta segunda interpretación y ello porque para la primera, la referencia a los derechos históricos resulta por completo superflua. Cataluña puede asumir esas competencias sin necesidad de apelación alguna a hipotéticos derechos históricos.

En definitiva, el Tribunal defiende la constitucionalidad de la fórmula catalana en la medida en que en ningún momento hace referencia a la DAP. Sin embargo, esto lejos de solucionar el problema lo agrava. Si el Estatuto catalán no se refiere a los derechos históricos de la DAP (porque están reservados a las Provincias Vascas y a Navarra) ¿a qué derechos históricos se está refiriendo?, ¿cuál es su contenido?, y sobre todo, ¿qué finalidad persiguen?. A partir de ahora el bloque de constitucionalidad reconocerá la existencia de unos «derechos históricos»-carentes de fundamento constitucional- cuyo contenido real y alcance sólo el futuro (y no la historia) podrán determinar.

La admisión por parte del Tribunal de unos derechos históricos y de una posición singular de Cataluña, abre la puerta a una indefinida espiral reivindicativa. Baste, a título de ejemplo, recordar unas declaraciones de uno de los «padres» del nuevo Estatuto, el dirigente de CIU F. Homs. El político catalán defendía con entusiasmo las «potencialida-

18 Tudela Aranda, J.: «La Disposición Adicional Primera y los nuevos Estatutos de Autonomía..., ob. cit., pág. 169-170. 
des jurídicas» del Estatuto, y entre ellas ocupaba un lugar destacado el reconocimiento de los derechos históricos de Cataluña: «los derechos históricos sirven para ampliar competencias, porque son los que de verdad dan contenido a la nacionalidad, al hecho diferencial, en términos constitucionales» ${ }^{19}$.

Por todo lo expuesto, compartimos la tesis de los magistrados discrepantes, partidarios de anular las referencias del Preámbulo y del artículo 5. Y ello porque creemos que no resulta lícito interpretar el artículo 5 en contra de su propio tenor literal, en contra de su propio sentido, en contra del significado real de la apelación a la historia como título legitimador de la singularidad catalana, en contra de lo que entienden la mayoría de los diputados que en Cataluña lo respaldaron...para concluir como hace el Tribunal que las referencias a los derechos históricos no suponen el reconocimiento de un principio de doble legitimidad. Por todo lo expuesto, creemos que las disposiciones impugnadas establecen ese principio y debieron ser anuladas.

Finalmente, la tercera de las disposiciones preambulares impugnadas, la referencia al derecho «inalienable» al autogobierno es declarada constitucional en el FJ 8, mediante un pronunciamiento interpretativo que implica una reconstrucción de la fórmula empleada y que, en definitiva, viene a dejar sin contenido alguno el adjetivo «inalienable»:

«El único sentido que cabe atribuir a la referencia del preámbulo del Estatuto al "derecho inalienable de Cataluña al autogobierno" es el de la afirmación de que tal derecho no es sino el que el art. $2 \mathrm{CE}$ "reconoce y garantiza" a las "nacionalidades y regiones" que integran aquélla. Derecho constitucional, por tanto, y, en virtud de esa cualidad, inalienable, esto es, indisponible para los poderes constituidos, y sólo al alcance del poder de revisión constitucional. En virtud del entendimiento antes expresado ha de ser desestimada la impugnación de la expresión «derecho inalienable de Cataluña al autogobierno» contenida en el preámbulo del Estatuto» (FJ 8).

El Tribunal pasa por alto que el artículo 2 de la Constitución no contiene el adjetivo «Inalienable» y que dicha omisión no fue involuntaria. Cuando el constituyente quiso definir un derecho como inviolable lo hizo, por ejemplo en el 10.

El Tribunal reinterpreta por tanto la disposición preambular pero la seguridad jurídica sufre, una vez más, puesto que se trata de un pronunciamiento que no es llevado expresamente al Fallo.

\section{CONCLUSIONES}

Las referencias preambulares a la nación y a la realidad nacional, las disposiciones relativas a los derechos históricos y al derecho inalienable al autogobierno tienen en común como el propio Tribunal reconoce remitirse al fundamento del Estatuto.

En modo alguno puede minusvalorarse la importancia de unas disposiciones preambulares que tienen reflejo directo en normas del articulado y remiten a la cuestión política por antonomasia: la legitimidad del Estatuto, su origen o fundamento político.

19 La Vanguardia, 11 de setiembre de 2006. 
El Tribunal en todos sus pronunciamientos sobre estos extremos es claro, rotundo y contundente: no hay más fundamento del autogobierno y de la autonomía de Cataluña que el poder constituyente del pueblo español, titular de la soberanía y autor de la CE de 1978.

Con estos pronunciamientos claros y rotundos, en principio, el Tribunal ha cumplido con su función de defensor de la Constitución, y garantizado la adecuación del Estatuto catalán a la Constitución española ${ }^{20}$.

El Tribunal, con los pronunciamientos analizados en las páginas precedentes, - $-\mathrm{y}$ a pesar de haber introducido una buena dosis de inseguridad jurídica como consecuencia de la falta de anulación expresa de los preceptos materialmente inconstitucionales- ha desactivado, en buena medida, la que podríamos considerar inconstitucionalidad global del texto estatutario en la medida en que éste pudiera exigir ser interpretado como una norma fundamental emanada de un poder originario: una nación dotada de unos derechos históricos y de un derecho inalienable al autogobierno, y no como una norma derivada de la Constitución y que sólo en ella y en el poder constituyente del pueblo español encuentra su único y exclusivo fundamento.

Ahora bien, la impecable doctrina del Tribunal conduce de forma directa y obligada a declarar la inconstitucionalidad y subsiguiente nulidad de las disposiciones impugnadas (Preámbulo, artículo 5 y artículo 8) y sin embargo, el Tribunal ha eludido la declaración de inconstitucionalidad. La técnica de la interpretación conforme le ha permitido privar de efectos a decenas de artículos y a varias disposiciones preambulares sin tener que anularlos. Desde un punto de vista jurídico, se trata de un expediente muy criticable. El principio de conservación de las normas exige que cuando un precepto legal sea susceptible de varias interpretaciones, y alguna de ellas sea constitucional, el Tribunal debe optar por ella para evitar anular la ley. Pero, cuando el precepto sólo admite interpretaciones contrarias a la Constitución, no es lícito forzar la letra de la ley para hacerle decir lo contrario de lo que pretende y evitar así su anulación. Y esto es lo que ha hecho de forma reiterada el Tribunal. En estas páginas he puesto de manifiesto la reconstrucción de los artículos 5 y 8 en relación con las disposiciones preambulares relativas a la nación y a los derechos históricos. Esta técnica supone una extralimitación de las funciones del Tribunal que no está facultado para reconstruir las normas impugnadas. En esto radica la discrepancia fundamental de los votos particulares formulados por algunos magistrados.

Por último, no podemos dejar de mostrar nuestra inquietud respecto a la ejecución de la sentencia. En la medida en que se trata de una sentencia interpretativa, serán los actores políticos implicados (titulares de los poderes centrales y del poder autonómico catalán) los que deberán aplicar el Estatuto en el sentido indicado por el Tribunal Constitucional ${ }^{21}$.

20 Así lo entiende también MuÑOZ MACHADO: «las competencias materiales que atribuye el Estatuto de 2006 a la Generalitat no son sustancialmente más amplias que las que ya tenía reconocidas. Pero el origen y la legitimidad de sus poderes se atribuyeron, de un modo nada larvado, a la decisión de un nuevo soberano, que radicaba en el territorio estatuyente, con un rango paralelo al constituyente español. La radical dificultad de integrar estos nuevos planteamientos en el marco de la Constitución vigente es lo que ha determinado los procedimientos más decisivos de la sentencia que, sobre todo, ha negado a Cataluña el carácter de nación soberana, ha desarbolado la idea de que el origen de su poder pueda radicar en el pueblo de Cataluña y sus derechos históricos...», El Imparcial, 29 de junio de 2010.

21 También alude a ello BLANCO VALDÉS para quien el otro gran problema de las sentencias interpretativas es «la posibilidad de que el principal destinatario de las mismas..las desconozca». BLANCO VALDÉs, R.: «El Estatuto catalán y ...», ob. cit., pág. 18. 
Baste recordar que la más importante de las sentencias interpretativas dictadas por el Tribunal Constitucional, la relativa a la constitucionalidad de la designación por el Parlamento de los veinte vocales del Poder Judicial ha sido manifiestamente incumplida por los partidos políticos actuantes en el Parlamento. Por decirlo con mayor claridad y contundencia, con aquella Sentencia el Tribunal no garantizó la supremacía normativa efectiva del Texto Constitucional, lo que ha supuesto que en relación a un elemento esencial de la arquitectura constitucional (la independencia judicial) la Constitución sea violada.

Desde esta óptica la reacción política que ha suscitado la sentencia no deja de producir una honda preocupación. Por una parte, el Gobierno habla de «rescatar» el Estatuto, concibiendo ese rescate como una forma de eludir los efectos de la sentencia. Y por otra, y en relación concreta con el tema abordado en este trabajo, los dirigentes políticos y sociales catalanes impulsores del nuevo Estatuto respondieron con una manifestación cuyo lema era: «Som una nació. Nosaltres decidem» (Somos una nación. Nosotros decidimos). Si la primera parte resulta tan legítima como inocua, no ocurre lo mismo con la segunda. El lema traduce políticamente el vicio de inconstitucionalidad global que invalidaba el Estatuto y que con mayor o peor fortuna el Tribunal ha depurado. La consecuencia que se predica del ser nacional es el derecho a decidir el futuro de España. En este sentido lo que ha hecho el Tribunal en los Fundamentos Jurídicos que hemos analizado es recordar que las nacionalidades y regiones no tienen ningún derecho a decidir por su cuenta y de forma soberana. Dicho con otras palabras: autonomía no es soberanía (STC 4/1981).

La única nación titular de un derecho a decidir es la española, y ese derecho sólo puede hoy ejercerse (al margen de mediante la apertura de un nuevo proceso constituyente, lo que política y jurídicamente carece por completo de sentido) a través del poder constituyente constituido, esto es, el poder de reforma.

El problema es que esta evidencia sigue siendo ignorada por lo que cabe temer nuevos intentos de alterar el marco constitucional a través de normas infraconstitucionales, esto es, de modo ilegítimo. Frente a ello sólo cabe seguir insistiendo en la necesidad de afrontar nuestros problemas de organización territorial mediante la reforma constitucional.

$* * *$

TITLE: The Constitutional Court case on the Preamble of the Statute of Autonomy of Catalonia: nation, national reality and historical rights.

AbSTRACT: This paper examines the Constitutional Court case on the Preamble of the Statute of Autonomy of Catalonia (STC 31/2010). For the Spanish Court, the Statute cannot be regarded as an original Constitution derived from a constituent power. On the contrary, the Statute is a law derived from the Spanish Constitution. From this point of view, we analyze the following issues: a) first, the possibility of a constitutional control of the preambles of the laws; b) secondly, the question about the meaning and scope of the effectiveness of the preamble regarding the terms of nation and national reality of Catalonia; c) thirdly, the reasoning of the Courts on bistorical law.

ResUMEN: En este trabajo se examina el pronunciamiento del Tribunal Constitucional relativo al Preámbulo del Estatuto de Autonomía de Cataluña (STC 31/2010). Su importancia reside en que con él se desactiva en buena manera, la que podríamos considerar inconstitucionalidad global del texto estatutario en la medida en que pudiera exigir ser interpretado como una norma fundamental emanada de un poder originario: una nación dotada de unos derechos bistóricos y de un 
EL PRONUNCIAMIENTO DEL TRIBUNAL CONSTITUCIONAL SOBRE EL PREÁMBULO DEL ESTATUTO... 447

derecho inalienable al autogobierno, y no como una norma derivada de la Constitución y que sólo en ella y en el poder constituyente del pueblo español encuentra su único y exclusivo fundamento. Con estas premisas, se analizan las siguientes cuestiones: a) en primer lugar, la idoneidad del Preámbulo para ser objeto de un pronunciamiento del Tribunal Constitucional; b) en segundo lugar, el significado y alcance de la declaración contenida en el apartado primero del fallo sobre la privación de eficacia jurídica interpretativa a las referencias a la nación y a la realidad nacional de Cataluña; c) en tercer lugar, el pronunciamiento del Tribunal sobre los? derechos históricos?

KeY Words: Preambles. Nation. Nationalities. Interpretative sentences. Historical law.

Palabras Clave: Preámbulos. Nación. Nacionalidades. Sentencias interpretativas. Derechos históricos.

FECHA DE RECEPCIÓN: 04.10.2010. FECHA DE ACEPTACIÓN: 26.01.2011

UNED. Teoría y Realidad Constitucional, núm. 27, 2011, pp. 423-448. 
11 12/05/2011 7:36 Página 448 